\title{
Nível de conhecimento e práticas de hidratação em atletas de futebol de categoria de base
}

\author{
Level of knowledge and hydration strategies of young \\ soccer players
}

\author{
Fabrícia Geralda Ferreira ${ }^{1}$ \\ Janaina Lubiana Altoé 1 \\ Rafael Pires da Silva 1 \\ Lilyane Perny Tsai ${ }^{1}$ \\ Alex de Alexandre Fernandes ${ }^{1}$ \\ Ciro José Brito 2 \\ João Carlos Bouzas Marins ${ }^{1}$
}

1 Universidade Federal de Viçosa, Departamento de Educação Física. Viçosa, MG. Brasil.

2 Centro Universitário Metodista de Minas Izabela Hendrix. Belo Horizonte, MG. Brasil.

Recebido em 27/05/08 Revisado em 20/07/08 Aprovado em 07/11/08
Resumo - O objetivo deste trabalho foi investigar o nível de conhecimento e hábitos de hidratação de atletas de futebol da categoria de base. Foram avaliados 216 atletas do sexo masculino, com idade média de 18 \pm 0,9 anos, pertencentes a clubes da primeira e da segunda divisão de quatro Estados brasileiros, possuindo em média 8,7 $\pm 2,6$ anos de prática na modalidade. A metodologia empregada foi do tipo exploratória, através de uma pesquisa descritiva, utilizando-se um questionário composto por 18 perguntas objetivas auto-administrado. Os principais resultados indicaram que 32,3\% e 30,1\% dos atletas em competições e treinamentos, respectivamente, não apresentam estratégia de consumo de líquidos apropriada. Um total de 1,4\% e 4,6\% informou que nunca hidratam em treinamento e competição, respectivamente. Quando questionados sobre a solução (água ou isotônico) consumida antes, durante e após o exercício, a água apresentou maior índice de resposta em todos os momentos. Aproximadamente, 80 atletas, se hidratam somente após a sensação de sede. Dentre as soluções ingeridas, a Coca-Cola ${ }^{\circledR}$ aparece com 11,1\% de adeptos. Somente 27,8\% registram o peso corporal freqüentemente e 54,16\% afirmaram não ter idéia de como deve ser realizada uma adequada hidratação. Os sintomas mais comuns apresentados pelos atletas foram câimbras $(53,2 \%)$, sede intensa $(37,5 \%)$ e dor de cabeça (33,8\%). Esses resultados sugerem que os jogadores de futebol da categoria de base apresentam uma série de hábitos inadequados de hidratação, o que pode propiciar menor rendimento nos treinamentos e competições.

Palavras-chave: Hidratação; Desidratação; Nutrição.

Abstract - The aim of this study was to investigate fluid replacement strategies of young soccer players and their level of knowledge regarding hydration management. A total of 216 males (age: $18 \pm 0.9$ years) playing soccer for $8.7 \pm 2.6$ years were studied. The participants were members of four elite and subelite Brazilian soccer clubs. An exploratory descriptive study was conducted using a self-administered questionnaire consisting of 18 objective questions. The main results indicated that $32.3 \%$ and $30.1 \%$ of the athletes do not have an appropriate strategy for fluid replacement during competitions and training, respectively. In addition, $1.4 \%$ and $4.6 \%$ of the subjects reported to ingest no fluids during these exercise conditions. When asked about the type of solution (water or isotonic solution) consumed before, during and after exercise, water was the main fluid ingested during these periods. Approximately 80 athletes only ingest fluids when feeling thirsty. Coca-Cola ${ }^{\circledR}$ accounted for $11.1 \%$ of ingested fluids. Only $27.8 \%$ of the participants measure their body weight and $54.2 \%$ were unaware of the adequate strategy for fluid replacement. The most common symptoms reported by the athletes were cramps (53.2\%), intense thirst (37.5\%), and headache (33.8\%). These results suggest that young soccer players have inappropriate fluid replacement habits, a fact that may lead to low performance during training or competition.

Key words: Hydration; Dehydration; Nutrition. 


\section{INTRODUÇÃO}

O futebol caracteriza-se como uma atividade intermitente que alterna momentos de alta e baixa intensidade ${ }^{1}$. Tais atividades quando realizadas em condições ambientais extremas como, por exemplo, locais com temperatura e umidade relativa do ar elevadas, impõem aos jogadores uma acentuada perda hídrica que associada à baixa ingestão de fluidos, contribui para ocorrência da desidratação² .

Observa-se que a desidratação além de ocasionar queda de rendimento, muitas vezes propicia agravos à saúde do esportista ${ }^{3-6}$, sendo que para minimizar sua ocorrência, é necessário estabelecer estratégias de reposição hídrica antes, durante e depois do exercício².

Para estabelecer corretamente estas estratégias no futebol, devem ser levados em consideração os fatores que alteram a perda hídrica, tais como, as condições climáticas (temperatura e umidade) no evento esportivo, as demandas fisiológicas imposta pela modalidade, o estado de aclimatação dos jogadores, a condição física dos atletas, as especificidades de cada jogo e / ou treino, a falta de pausas regulares para ingestão de líquidos durante a partida e a taxa de sudorese $\mathrm{e}^{7-9}$.

A determinação da perda hídrica de cada atleta e consequentemente a definição da quantidade de líquido a ser reposta, pode ser obtida por meio da realização da pesagem corporal antes e após os treinamentos e competições.

Constata-se que, no futebol, a perda hídrica dos jogadores durante as partidas são extremamente variáveis, como pode ser demonstrado pelos estudos de Maughan et. al..$^{10}$ e Aragon-Vargas et al..$^{11}$ que encontraram, respectivamente, perda de 1,15\% e 3,38\% da massa corporal. Caso a perda hídrica resulte em um percentual de $5 \%$ de desidratação, a capacidade de trabalho do atleta pode ser reduzida em até $30 \%{ }^{4}$, sendo que a capacidade cognitiva pode ser prejudica$\mathrm{da}^{5,6}$, alterando completamente o desempenho.

Diante desses fatores, o procedimento, o momento e o tipo de líquido usado para hidratar podem ser determinantes no conjunto de variáveis que interferem nos resultados de uma partida ou na qualidade do treino.

Com relação ao tipo de líquido a ser usado para hidratar nas partidas de futebol, temos as bebidas carboidratadas que são classificadas pela ANVISA ${ }^{12}$ em repositores hidroeletrolíticos e em repositores energéticos. Os primeiros são produtos formulados a partir de diferentes concentrações de eletrólitos, associados a concentrações variadas de carboidra- tos, que objetivam a reposição hídrica e eletrolítica proveniente da prática de atividade física. Estes produtos devem conter concentrações variadas de sódio, cloreto e carboidratos e opcionalmente, potássio, vitaminas e ou minerais. Entre os repositores hidroeletrolíticos, os isotônicos são os produtos que apresentam osmolalidade próxima da plasmática $(285 \mathrm{mOsmol} / \mathrm{L})$, o que, consequentemente facilita a restauração hídrica. Os repositores energéticos são os produtos formulados com nutrientes que permitem o alcance e ou manutenção do nível apropriado de energia para atletas. Entre os nutrientes energéticos presentes na formulação da bebida, os carboidratos devem constituir, no mínimo, 90\% destes, sendo opcional a introdução de vitaminas e ou minerais.

O efeito do consumo de bebidas carboidratadas na habilidade em testes específicos, após uma partida de futebol foi investigado por Ostojic e Mazic ${ }^{13}$ que observaram uma melhora na performance nestes testes, o que demonstra que o consumo de carboidrato pode ser válido quando se pretende prevenir a queda de rendimento do atleta, bem como o de sua equipe.

Diante das evidências que a hidratação interfere na performance dos jogadores de futebol, o conhecimento sobre os hábitos e as práticas de hidratação dos jogadores das categorias de base, assim como da comissão técnica, é imprescindível para um adequado planejamento da reposição hídrica durante treinamentos e competições, sendo que, durante as partidas a reposição de líquidos é dificultada pela própria dinâmica da modalidade. Nesse sentido, o objetivo deste trabalho foi investigar o nível de conhecimento e hábitos de hidratação de atletas de futebol da categoria de base.

\section{PROCEDIMENTOS METODOLÓGICOS}

Para o desenvolvimento deste trabalho, empregouse uma metodologia exploratória, por meio de uma investigação descritiva. Os procedimentos adotados foram: seleção de instrumento de coleta de dados; treinamento dos sujeitos para aplicação do instrumento de testagem e coleta de dados.

\section{Instrumento}

Como instrumento para coleta de dados, foi utilizado um questionário padronizado, contendo 18 perguntas objetivas relacionadas à hidratação, já aplicado anteriormente em outros estudos ${ }^{14-17}$.

\section{Característica da Amostra}

Participaram deste estudo 216 atletas do sexo 
masculino, com média de idade de 18 0 0,9 anos, pertencentes a clubes da primeira e da segunda divisão de quatro Estados brasileiros (Goiás, Minas Gerais, Rio de Janeiro e São Paulo). Eles possuíam, em média, 8,7 $\pm 2,6$ anos de prática na modalidade e treinavam, em média, 5 vezes por semana, no mínimo, 2 horas em cada sessão.

Este estudo foi aprovado pelo Comitê de Ética em Pesquisa com Seres Humanos da Universidade Federal de Viçosa, de acordo com a resolução do Conselho Nacional de Saúde nº 196/96. Os avaliados foram devidamente informados sobre o objetivo da pesquisa e aqueles que aceitaram participar do estudo assinaram um termo de consentimento livre e esclarecido.

\section{Coleta de Dados}

O questionário utilizado neste estudo foi autoadministrado durante os treinamentos e/ou competições, estando os pesquisadores presentes durante todo o tempo para esclarecer eventuais dúvidas.

\section{Tratamento Estatístico}

$\mathrm{Na}$ análise estatística, utilizou-se a distribuição percentual obtida em cada resposta, descartando as questões não respondidas.

\section{RESULTADOS}

Este tópico apresenta os resultados das perguntas contidas no questionário relacionadas à hidratação, de acordo com a ordem de elaboração.

A Figura 1 apresenta o índice de respostas obtidas relacionada ao hábito de hidratação dos atletas em treinamento e competições, no que se refere à freqüência do consumo de líquidos, que variava desde ausência (nunca) até o consumo sistemático (sempre).

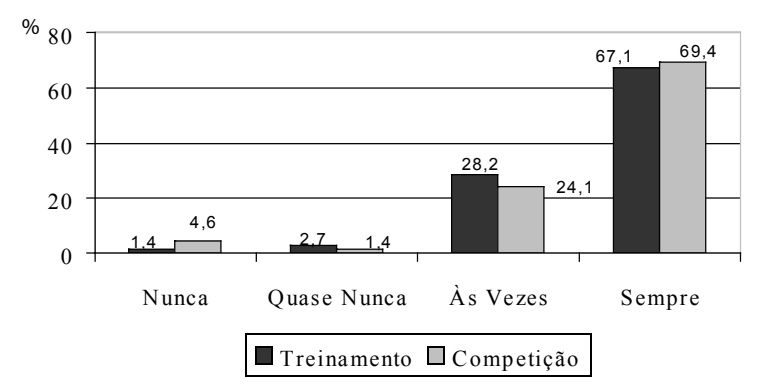

Figura 1. Costume de hidratação dos atletas de futebol.

Na Figura 2, é estratificado como ocorre o consumo de líquido nos momentos antes, durante e depois dos treinamentos e competições, obser- vando-se a semelhança entre ambos, o que indica que as condições da competição são reproduzidas nos treinamentos.

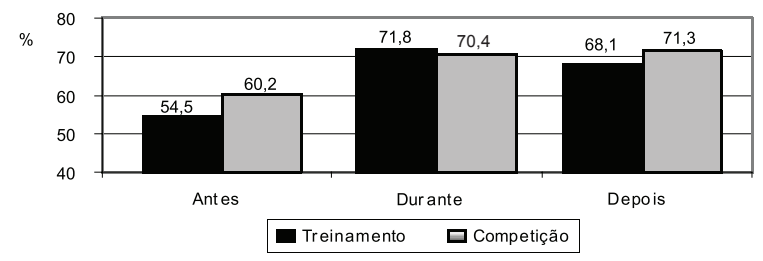

Figura 2. Momento de hidratação dos jogadores de futebol.

Com relação à preocupação com o tipo de líquido que ingerem, um total de 78,3\% afirmou preocupar-se com o que utilizam para hidratar-se. Contudo, quando questionados sobre a solução (água ou isotônico) consumida antes, durante e após o exercício, a água apresentou maior índice de resposta em todos os momentos (Figura 3).

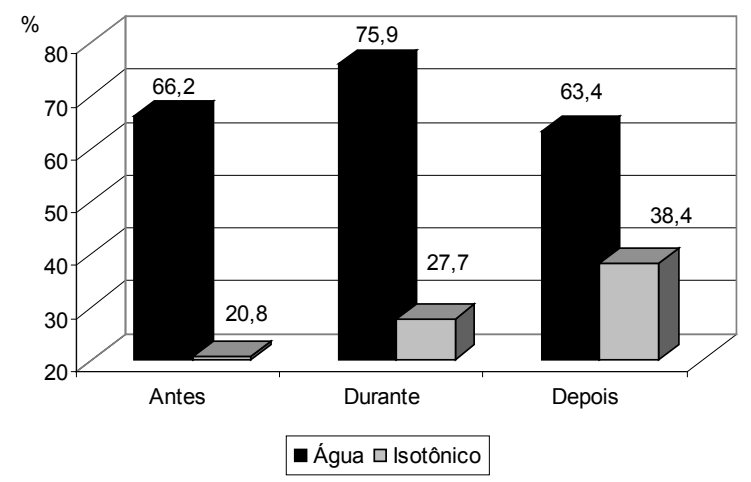

Figura 3. Consumo de água e isotônico em diferentes momentos de atividade.

Visando identificar a sensação de sede como indicador para iniciar o processo de hidratação, verificouse que $63 \%$ dos atletas afirmaram que a hidratação deve ser realizada antes da sensação de sede.

Quando questionados sobre quais os líquidos utilizam para se hidratar, constatou-se que a água é a solução mais utilizada (88\%), seguida dos sucos naturais $(51,4 \%)$ e isotônicos (39,4\%). Constatouse, ainda, o consumo de refrigerantes como CocaCola $^{\circledR}$, com $11,1 \%$ de adeptos.

Ao serem questionados sobre as marcas de isotônicos, observou-se que o Gatorade ${ }^{\circledR}$ era a mais conhecida entre os atletas, seguido de Energil $\mathrm{C}^{\circledR}$, sendo estes dois os de maior preferência (Tabela 1). Já entre as opções de sabor, laranja (39,8\%), tangerina $(30,5 \%)$ e limão $(18,5 \%)$ apareceram como os preferidos.

Quanto ao hábito de hidratação nas diferentes estações do ano, verificou-se que a maior preocupação era manifestada no período de verão $(51,4 \%)$. 
A utilização da técnica de pesagem antes e depois da atividade desportiva é uma forma fácil e prática de estabelecer a quantidade de líquido que deve ser reposta ao final de uma sessão de treinamento ou competição, devendo ser realizada pelos atletas. Neste estudo, somente $27,8 \%$ registram o peso corporal freqüentemente, com a soma dos que "nunca" e "quase nunca" utilizam tal técnica atingindo $32 \%$.

Uma das perguntas contidas no questionário relacionava-se com os sintomas ocorridos, pelo menos, uma vez durante os treinamentos e competições. A Tabela 2 apresenta os resultados obtidos.

Tabela 1. Bebidas mais conhecidas e índice de preferência.

\begin{tabular}{lcc}
\hline Bebidas & $\begin{array}{c}\text { Qual solução } \\
\text { você conhece? }\end{array}$ & $\begin{array}{c}\text { Qual de sua prefe- } \\
\text { rência? }\end{array}$ \\
\hline Nenhuma & $0,9 \%$ & $0 \%$ \\
Sportdrink $^{\circledR}$ & $16,2 \%$ & $6,5 \%$ \\
Marathon $^{\circledR}$ & $51,8 \%$ & $5,1 \%$ \\
Gatorade $^{\circledR}$ & $89,8 \%$ & $81 \%$ \\
Energil C $^{\circledast}$ & $63 \%$ & $22,2 \%$ \\
Redbull $^{\circledR}$ & $44,4 \%$ & $11,1 \%$ \\
SportAde & & $1,4 \%$ \\
Outros & $6,5 \%$ & $1,4 \%$ \\
\hline
\end{tabular}

Tabela 2. Sintomas relatados pelos atletas durante a atividade

\begin{tabular}{lc}
\hline Sinais de Desidratação & $\begin{array}{c}\text { Índice de Res- } \\
\text { postas }\end{array}$ \\
\hline Câimbras & $53,2 \%$ \\
Sede intensa & $37,5 \%$ \\
Dor de cabeça & $33,8 \%$ \\
Sensação de perda de força & $22,2 \%$ \\
Dificuldade de concentração & $12 \%$ \\
Dificuldade de realização de um movi- & $10,6 \%$ \\
mento técnico & $9,7 \%$ \\
Fadiga generalizada & $8,8 \%$ \\
Alterações visuais & $8,3 \%$ \\
Sonolência & $6,9 \%$ \\
Desmaios & $4,2 \%$ \\
Palidez & $2,3 \%$ \\
Olhos fundos & $1,8 \%$ \\
Convulsões & $1,4 \%$ \\
Perda momentânea da consciência & $0,9 \%$ \\
Insensibilidade nas mãos e pés & $0,9 \%$ \\
Interrupção da produção do suor & $0,5 \%$ \\
Alucinações & $0,5 \%$ \\
\hline Interrupção da atividade planificada &
\end{tabular}

Com a finalidade de investigar o conhecimento dos atletas sobre as estratégias de hidratação, em termos de quantidade e freqüência de ingestão de líquidos, identificou-se que apenas $26,4 \%$ assinala- ram a resposta correta que era " $1 / 4$ de líquido para cada $1 / 4$ de hora". Entretanto, $54,2 \%$ dos entrevistados afirmaram não ter idéia de como deve ser realizada uma adequada hidratação.

Outro fator que pode agravar a perda hídrica, investigado neste estudo é a vestimenta utilizada durante a prática desportiva. Fatores como cor, tipo e quantidade de tecido podem influenciar diretamente o desempenho. Dos atletas, 83,4\% afirmaram preocupar-se com o tipo de vestimenta que utilizam, com a maior preocupação manifestada para o tipo de tecido $(51,8 \%)$, seguido da quantidade $(27,8 \%)$ e da cor $(13,4 \%)$.

Com relação à temperatura do líquido, identificou-se que a maior parte dos entrevistados prefere que esteja moderadamente gelado (63,9\%), enquanto 29,6\% preferem que esteja à temperatura normal, ou seja, na temperatura ambiente, e apenas 7,4\% relataram gostar de líquidos extremamente gelados.

A orientação nutricional exerce um papel preponderante nas escolhas das estratégias e práticas de hidratação, o que, consequentemente, poderá influenciar o rendimento. Neste trabalho, $77,3 \%$ dos entrevistados afirmaram já ter recebido informações sobre a melhor maneira de hidratar-se; portanto, é necessário identificar se essas informações estão ou não sendo prestadas por profissionais qualificados.

Dessa forma, dentre os atletas que afirmaram ter recebido orientação, o preparador físico destacou-se como o profissional responsável pela maioria das informações $(63,9 \%)$, seguido de médicos $(21,3 \%)$ e livros/revistas (10,2\%).

A última pergunta do questionário referia-se ao conhecimento sobre a função dos isotônicos, por acreditarmos que este conhecimento pode auxiliar no aumento do consumo dessa solução. Assim, como demonstra a Figura 4, boa parte dos atletas desconhece sua função.

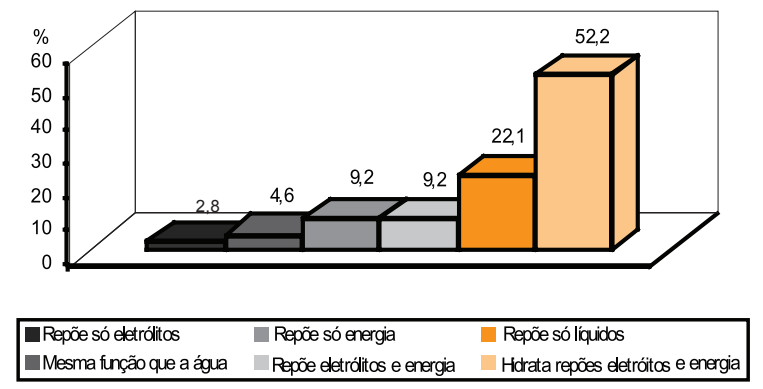

Figura 4. Conhecimento sobre as funções dos isotônicos.

\section{DISCUSSÃO}

É consenso a necessidade do consumo sistemático de líquidos durante o exercício, visando evitar ou 
minimizar um quadro de desidratação ${ }^{18,19}$. Como foi demonstrado na Figura 1, a maioria dos atletas sempre se hidrata nos treinamentos e competições, apresentando um hábito adequado para seu rendimento ${ }^{3,4}$. Contudo, $32,3 \%$ e 30,1\% dos avaliados, em treinamentos e competições, respectivamente, não apresentam estratégia de consumo de líquidos apropriada. Considerando que esses atletas constituem um grupo especial, pois sendo jogadores da categoria de base de clubes profissionais, eles necessitam continuamente de informações sobre os benefícios da hidratação, assim como os atletas em idade universitária avaliados por Nichols et al. ${ }^{20}$.

Apesar dos resultados de "nunca" e "quase nunca", identificados nos treinamentos e competições apresentarem um percentual menor do que os estudos com judocas ${ }^{15}$ e corredores europeus ${ }^{14}$, pode-se perceber uma falha por parte da comissão técnica desses clubes, já que um jogador desidratado poderá comprometer o seu rendimento e o da equipe ${ }^{18,19}$.

No entanto, aproximadamente metade dos atletas não se hidrata antes dos treinamentos $\mathrm{e}$ competições (Figura 2), impossibilitando a realização de uma hidratação preventiva, podendo assim, iniciar a atividade já desidratados.

Aqueles que afirmaram não ter o costume de hidratar-se durante o exercício apresentam risco aumentado de desidratação e hipertermia, principalmente, se as condições ambientais envolverem valores elevados de temperatura e umidade relativa do ar, fatores estes que facilitam a perda hídrica. Um exemplo da interferência de fatores ambientais na perda hídrica pode ser demonstrado pelos resultados dos estudos de Kirkendall ${ }^{21}$ e Mustafá e $\mathrm{Mahmoud}^{22}$, nos quais a diferença de temperatura $\left(19^{\circ} \mathrm{C}\right.$ e $33^{\circ} \mathrm{C}$, respectivamente) em que foram disputadas as partidas pode ter sido um dos principais fatores responsáveis pela diferença na perda de peso encontrada nestes estudos.

A hidratação após a atividade é fundamental para uma boa recuperação, pois, além de repor as perdas hidroeletrolíticas, pode, caso esteja associada à ingestão de carboidratos, restaurar as fontes energéticas, permitindo ao atleta uma recuperação mais rápida e eficiente para a próxima sessão de treino ou competição $0^{17}$. Entretanto, neste estudo, vários atletas não apresentaram esse hábito, podendo supostamente, ter o desempenho reduzido nas próximas partidas ou sessões de treinamento.

Constatou-se, neste estudo, uma baixa ingestão de isotônico (Figura 3), fato também observado em outros estudos, como o de Brito e Marins ${ }^{15}$, avaliando judocas, e o de Marins e Ferreira ${ }^{16}$, com atletas universitários, o que pode revelar que a menor ingestão de solução carboidratada não é comum apenas entre jogadores de futebol. É importante destacar que fatores como o desconhecimento da função do isotônico e a dificuldade na aquisição por razões financeiras podem ser pontos desfavoráveis ao consumo desse produto.

É importante destacar que ao se hidratar somente com água, os atletas apenas mantêm os estoques hídricos próximos da normalidade, enquanto que ao consumir soluções carboidratadas, além de restaurar os estoques hídricos, podem armazenar uma quantidade extra de carboidrato, que nos exercícios de longa duração é fundamental para minimizar a ocorrência de quadros de hipoglicemia $^{13}$. Essa ação auxilia também na restauração do glicogênio muscular pós-atividade, acelerando o processo de recuperação ${ }^{21}$, já que, dependendo do calendário esportivo, pode-se chegar a disputar até três partidas por semana.

Um erro comum dos desportistas é iniciar a ingestão de líquido após a sensação de sede. No entanto, este é um índice imperfeito do estado de desidratação, pois, quando o atleta se orienta por essa sensação, ele já está $2 \%$ desidratado 23 . Identificou-se neste estudo que 80 atletas apenas se hidratam após a sensação de sede, devendo modificar este hábito, a fim de amenizar a queda de rendimento proveniente da desidrataçãa ${ }^{24,25}$.

Esses 80 atletas representam 37,1\% da amostra, sendo superior ao valor encontrado no estudo de $\mathrm{Ma}$ rins e Ferreira ${ }^{16}$, nos quais $21,5 \%$ dos atletas universitários apresentavam hábito inadequado, revelando que os preparadores físicos e treinadores deveriam incentivar constantemente seus atletas à hidratação, como ocorre entre treinadores de atletas universitários americanos, em que 94\% deles estimulam o consumo de líquido durante as competições ${ }^{26}$.

Ao serem questionados sobre os tipos de líquidos que utilizam para hidratar, a presença de Coca$\mathrm{Cola}^{\circledR}$ entre eles revela um hábito inadequado, uma vez que o consumo de refrigerante pode estar relacionado com o aparecimento de desconforto gastrintestinal ${ }^{14-16}$. Um percentual expressivo foi também observado no estudo de Brito e Marins ${ }^{15}$, com $14,5 \%$ dos judocas afirmando consumir CocaCola ${ }^{\circledR}$ como hidratante; Marins e Ferreira ${ }^{16}$, com $13 \%$ entre os universitários; e maratonistas entrevistados por Marins et al. ${ }^{14} \mathrm{com} 12 \%$.

Com relação aos sucos naturais, observou-se elevado consumo, corroborando com os resultados de Brito e Marins ${ }^{15}$ e Marins e Ferreira ${ }^{16}$, demonstrando que atletas de diferentes modalidades são 
adeptos a esse líquido, hábito não tão presente entre os atletas espanhóis estudados ${ }^{14}$.

Este estudo demonstrou que o baixo consumo de isotônico apresentado pelos atletas não se deve ao desconhecimento, pois apenas $0,9 \%$ deles revelaram não conhecer esses produtos. Quanto ao fato de o Gatorade ${ }^{\circledR}$ ser o isotônico mais conhecido e o de maior preferência (Tabela 1), pode estar relacionado às estratégias de marketing utilizadas por esta multinacional, assim como à sua ampla distribuição nacional. O Energil $\mathrm{C}^{\circledR}$ pode ter se destacado como o segundo isotônico mais conhecido, pelo fato de já ter sido patrocinador de diversas equipes do futebol brasileiro.

A utilização de bebidas flavorizadas, aumentando a ingestão de líquido foi demonstrada na revisão de Coleman ${ }^{27}$. No entanto, é improvável que um atleta ingira bebidas com sabores desagradáveis, sendo que o sabor pode diferenciar-se quando se encontra em repouso e em exercício. Os sabores de maior preferência entre os jogadores de futebol também foram listados como preferidos pelos judocas $^{15} \mathrm{e}$ atletas universitários ${ }^{16}$.

Avaliando o hábito de hidratação dos atletas nas diferentes estações do ano, o recomendável é que não haja diferença entre estas, fato observado em somente $39,8 \%$ dos atletas, que relataram ter preocupação com a hidratação independentemente da estação climática, uma vez que, mesmo em situação de inverno, quando as médias térmicas se apresentam mais baixas, existe possibilidade de desidratação, decorrente da baixa ingestão de líquido associada à sua perda através dos mecanismos de convecção e condução.

Como a maior parte dos atletas (acima de 2/3) não utiliza a técnica de pesagem ficam impossibilitados de calcular, ainda que de forma indireta, sua perda hídrica e, conseqüentemente, estabelecer sua reposição.

Seguindo a mesma ótica, Ferreira et al. ${ }^{28}$, avaliando corredores, observaram que 76,8\% deles não se pesam freqüentemente. Resultado semelhante foi observado por Marins e Ferreira ${ }^{16}$, com $41 \%$ relatando não utilizá-la. Contrariamente, Corley et al. ${ }^{29}$ relataram que $60 \%$ dos treinadores utilizavam a técnica de controle corporal com seus atletas.

Uma possível explicação para o fato de alguns grupos de atletas não realizarem o controle do peso corporal é a possibilidade do desconhecimento sobre a aplicação e importância da técnica, ou mesmo quanto à temática hidratação, já que a aplicação da técnica de pesagem é rápida, fácil e de baixo custo, sendo viável, independentemente, do nível social dos atletas.
No futebol especificamente, podem-se repor as perdas hídricas com base na variação do peso corporal antes e após os treinamentos e competições, podendo-se adotar como estratégia de reposição 1 a 1,5 litro para cada quilo de peso perdido ${ }^{30}$, facilitando o processo de recuperação.

A indicação geral de ingestão de líquido durante a atividade é de 200 a $250 \mathrm{ml}$ de líquido a cada 15 minutos, correspondendo à alternativa correta proposta neste trabalho. Porém, como a maior parte dos atletas afirmou não ter idéia de como devem realizar a hidratação, podem ser levados a assumirem hábitos inadequados, como o não-consumo de líquidos ou o consumo em excesso, afetando negativamente o desempenho, já que a ingestão de grande volume pode causar desconforto gástrico ${ }^{3}$.

A vestimenta no futebol é um fator que pode influenciar sobremaneira a perda hídrica, principalmente em regiões onde as médias de temperatura são extremamente altas e os jogos e treinamentos ocorrem nos horários mais próximos aos centrais do dia.

A preocupação manifestada pelos atletas com o tipo de vestimenta é um bom indicador de que estes estão atentos a esse fator interveniente. Por outro lado, a baixa preocupação com a cor do tecido reflete a impossibilidade de decisão da cor do uniforme, já que isso está relacionado às cores do clube e com o "mando" de campo em cada partida; roupas de cores escuras promovem elevação da temperatura, pela maior absorção do calor em conseqüência da radiação solar ${ }^{29}$. Em contrapartida, a maior preocupação com o tipo de vestimenta pode estar refletindo o conhecimento das novas tecnologias usadas na confecção de uniformes, que facilitam a dissipação do calor.

Deve-se, no entanto, chamar atenção para o baixo índice de atletas que se preocupam com a quantidade de tecido. Quando tomam a decisão em ambiente de calor, de treinar ou competir, por exemplo, com camisas de manga longa ou adicionando outra camisa com slogan para comemorações eventuais, ocorre uma maior dificuldade na perda de calor, aumentando a produção de sudorese e consequentemente à desidratação.

Quanto aos sintomas relatados na Tabela 2, destacando-se a alta incidência de "câimbras", podendo estar relacionadas, entre outros motivos, a desidratação e hipoglicemia decorrentes de um consumo inadequado de líquidos e bebidas carboidratadas ${ }^{18,19}$ "sede intensa", que poderia ser amenizada pela adoção de uma estratégia de hidratação com quantidade e freqüência adequada de reposição líquida ${ }^{18,19}$. Essas manifestações, assim como, "dor 
de cabeça"; "sensação de perda de força"; e "dificuldade de concentração" que obtiveram índices altos de manifestação, diminuem a qualidade dos movimentos e desestruturam a tática da equipe, podendo culminar em derrota.

A temperatura do líquido que deve ser utilizada na hidratação está diretamente relacionada com a preferência individual, contudo as bebidas refrigeradas tendem a ter uma maior palatabilidade estimulando o consumo ${ }^{18,19}$.

No que se refere às fontes de informações dos atletas sobre a temática hidratação, a participação da comissão técnica é importante, já que ela exerce influência direta sobre os atletas. Contrariamente aos achados deste estudo, Rockwell et al. ${ }^{26}$ afirmaram que as recomendações por parte dos técnicos para hidratação durante competições não são frequentes entre triatletas, com somente $22 \%$ dos treinadores recomendando aumentar o consumo de líquido durante as competições.

Outro ponto a ser destacado é a qualidade das informações prestadas. Fontes não confiáveis como internet, amigos e familiares, podem prestar informações inadequadas induzindo a um procedimento inadequado de hidratação.

Como demonstrado na Figura 4, um percentual baixo de atletas sabem a correta função de um isotônico, já que anteriormente, 77,3\% relataram já ter obtido informações sobre as melhores formas de se hidratar. Esperava-se que estes estivessem devidamente informados sobre os isotônicos, porém, isso não foi observado, o que mais uma vez requer atenção sobre a qualidade das informações prestadas.

O baixo consumo de isotônicos relatado por parte dos atletas anteriormente, pode ser em parte justificado pelo desconhecimento da função correta deste por quase metade dos atletas (48\%).

Entre as limitações deste estudo está na aplicação do questionário, uma única vez, no grupo investigado, o que impossibilita a verificação da fidedignidade e reprodutibilidade do método empregado para este grupo. É também necessário em estudos futuros ampliar o número de clubes de futebol investigados, pois tomando por base apenas 4 clubes, sendo que três deles são da região sudeste, não se pode generalizar os dados encontrados. Sugere-se, ainda, que sejam também avaliados jogadores da categoria profissional.

\section{CONCLUSÃO}

Os dados observados levam à conclusão de que a preocupação com a hidratação por parte dos atle- tas de futebol é aproximada entre os treinamentos e competições, indicando que as condições da competição são reproduzidas nos treinamentos. Entretanto, 30,1\% e 32,3\%, respectivamente, não consomem líquidos de forma apropriada, percentual este preocupante, principalmente, por se tratar de equipes pertencentes a clubes profissionais participantes do calendário esportivo brasileiro. Os atletas precisam ser melhor conscientizado sobre os benefícios da hidratação, pois um jogador desidratado poderá comprometer o seu rendimento e o de sua equipe.

O consumo de isotônicos por esse grupo de atletas é relativamente baixo, necessitando ser implementado para evitar os sintomas hipoglicêmicos, assim como aumentar a performance dos atletas. Entre os isotônicos selecionados, o Gatorade ${ }^{\circledR}$ é o mais conhecido, sendo o sabor laranja o de maior preferência. Dos sintomas relatados pelos atletas, destacou-se em primeiro lugar a câimbra, seguida de sede intensa e dor de cabeça. Tais resultados indicam que, possivelmente, uma estratégia de hidratação adequada poderia minimizar a ocorrência desses sintomas. Entre as estratégias a serem implementadas, sugerem-se, a ingestão de líquidos antes mesmo da sensação de sede, o aumento do consumo de isotônicos e a utilização da técnica de pesagem para restabelecer o equilíbrio do corpo. Essas são medidas simples que podem contribuir para uma correta hidratação, porém, neste trabalho, uma parcela expressiva dos entrevistados não as emprega em suas práticas de hidratação.

\section{REFERÊNCIAS BIBLIOGRÁFICAS}

1. Guerra I, Chaves R, Barros TL, Tirapegui J. The influence of fluid ingestion on performance of soccer players during a match. J Sports Sci Med 2004; 3(4):198-202.

2. Galloway SD. Dehydration, rehydration, and exercise in the heat: rehydration strategies for athletic competition. Can J Appl Physiol 1999;24(2):188-200.

3. Burke LM, Hawley JA. Fluid balance in team sports. Guidelines for optimal practices. Sports Med. 1997;24(1):38-54.

4. Horswill CA. Effective fluid replacement. Int J Sports Nutr 1998;8 (2):175-195.

5. Tomporowski PD, Beasman K, Ganio MS, Cureton K. Effects of dehydration and fluid ingestion on cognition. Int J Sports Med 2007;28(10):891-896.

6. Adam GE, Carter R 3rd, Cheuvront SN, Merullo DJ, Castellani JW, Lieberman HR, Sawka MN. Hydration effects on cognitive performance during military tasks in temperate and cold environments. Physiol Behav 2008;18;93(4-5):748-756. 
7. VARGAS LFA. Hidratação no futebol. In: BARROS TL, GUERRA I. organizadores. Ciência do futebol. Barueri: Manole; 2004. p. 85-99.

8. Godek SF, Bartolozzi AR, Burkholder R, Sugarman E, Peduzzi C. Sweat rates and fluid turnover in professional football players: a comparison of National Football League linemen and backs. J Athl Train 2008;43(2):184-189.

9. Godek SF, Bartolozzi AR, Godek JJ. Sweat rate and fluid turnover in American football players compared with runners in a hot and humid environment. Br J Sports Med 2005;39(4):205-211.

10. Maughan RJ, Shirreffes SM, Merson SJ, Horswill CA. Fluid and electrolyte balance in elite male football (soccer) players in cool environment. J Sports Sci 2005;23(1):73-79.

11. Aragon-Vargas LF, Moncada-Jiménez J, Solera AJ, Quesada HJ, Barrenechea A, Monge M. Thermoregulation and fluid balance during professional soccer competition in the heat. Med Sci Sports Exerc 2005,37(5):S29.

12. Agência de Vigilância Sanitária: Ministério da Saúde. Portaria n 222, de 24 de Março de 1998. 1998; Disponível em: http://e-legis.anvisa.gov.br/leisref/public/ showAct.php [2008 fev 09].

13. Ostojic SM, Mazic S. Effects of a carbohydrate-electrolyte drink on specific soccer tests and performance. J Sports Sci Med 2002;1(2):47-53.

14. Marins JCB, Argudo C, Iglesias ML, Marins N, Zamora S. Hábitos de hidratación en un colectivo de pruebas de resistencia. Selección 2004;13(1):18-28.

15. Brito CJ, Marins JCB. Caracterização das práticas sobre hidratação em atletas da modalidade de judô no estado de Minas Gerais. Rev Bras Ciênc Mov 2005;13(2):59-74.

16. Marins JCB, Ferreira FG Nível de conhecimento dos atletas universitários da UFV sobre hidratação. Fit Perf J 2005; 4(3):175-187.

17. Brito, I.S.S., Diniz, A.; Brito, C.J.; Marins, J.C.B. . Caracterização das práticas e hábitos de hidratação em lutadores brasileiros de jiu-jitsu. Coleção Pesquisa Educação Física 2007;6(3):153-160.

18. Casa DJ, Armstrong LE, Hillman SK, Montain SJ, Reiff RV, Rich BS, Roberts WO, Stone JA. National Athletic Trainers' Association Position Statement: Fluid Replacement for Athletes. J Athl Train 2000;35(2):212-224.

19. Sawka MN, Burke LM, Eichner ER, Maughan RJ, Montain SJ, Stachenfeld NS. American College of Sports
Medicine position stand. Exercise and fluid replacement. Med Sci Sports Exerc 2007;39(2):377-390.

20. Nichols PE, Jonnalagadda SS, Rosenbloom CA, Trinkaus M. Knowledge, attitudes, and behaviors regarding hydration and fluid replacement of collegiate athletes. Int J Sport Nutr Exerc Metab 2005;15(5):515-527.

21. Kirkendall DT. Effects of nutrition on performance in soccer. Med Sci Sports Exerc 1993;25(12):1370-1374.

22. Mustafa KY, Mahmoud NE. A. Evaporative water loss in African soccer players. J Sports Med Phys Fitness 1979;19(2):181-183.

23. Greenleaf J. Problem: thirst, drinking behavior, and involuntary dehydration. Med Sci Sports Exerc 1992;24(6):645-656.

24. Gisolfi C, Duchman SM. Guidelines for replacement beverages for different athetic events. Med Sci Sports Exerc 1992;24(6):679-687.

25. Sawka MN, Latzka WA, Matott RP, Montain SJ. Hydration effects on temperature regulation. Int J Sports Med 1998;19(Suppl 2):S108-110.

26. Rockwell M, Nickols-Richardson S, Thye W. Nutrition Knowledge, opinions, and practices of coaches and athletic trainers at a division I university. Int J Sport Nutr 2001;11(2):174-185.

27. Coleman E. Aspectos atuais sobre bebidas para esportistas. Sports Science Exchange [periódico on line]1996; 3. Disponível em: <http://www.gssi.com.br> [2008 marc 15].

28. Ferreira FG. Hidratação e perda hidromineral em corredores e indivíduos ativos. Tese de mestrado - Programa de Pós-Graduação em Ciência da Nutrição. Viçosa (Minas Gerais): Universidade Federal de Viçosa; 2007.

29. Corley G, Demarest-Litchford M, Bazzarre T. Nutrition Knowledge and Dietary Pratices of College Coaches. J Am Diet Assoc 1990;90:705-709.

30. Maughan R J, Shirrefs SM. "Dehydration, rehydration and exercise in the heat - concluding remarks". Int J Sports Med 1998;19:167-168.
Endereço para correspondência
João Carlos Bouzas Marins
Universidade Federal de Viçosa
Departamento de Educação Física
Laboratório de Performance Humana
CEP: 36571-000 - Viçosa, MG. Brasil
E-mail: jcbouzas@ufv.br 